Portland State University

PDXScholar

$1-1-2003$

\title{
"ARGUMENT IS WAR"-Or is it a Game of Chess? : Multiple Meanings in the Analysis of Implicit Metaphors
}

L. David Ritchie

Portland State University, cgrd@pdx.edu

Follow this and additional works at: https://pdxscholar.library.pdx.edu/comm_fac

Part of the Communication Commons

Let us know how access to this document benefits you.

Citation Details

Published as: Ritchie, D. (2003). " Argument is war"-or is it a game of chess? Multiple meanings in the analysis of implicit metaphors. Metaphor and Symbol, 18(2), 125-146.

This Post-Print is brought to you for free and open access. It has been accepted for inclusion in Communication Faculty Publications and Presentations by an authorized administrator of PDXScholar. Please contact us if we can make this document more accessible: pdxscholar@pdx.edu. 
Running head: $\quad$ IMPLICIT METAPHORS, MULTIPLE MEANINGS

ARGUMENT IS WAR - Or is it a Game of Chess?

Multiple Meanings in the Analysis of Implicit Metaphors

David Ritchie

Portland State University

Address correspondence to:

David Ritchie, Professor

Department of Communication

Portland State University

Portland, OR 97202-0751

(503) 725-3550

fax: (503) 725-5385

e-mail: cgrd@pdx.edu

Metaphor and Symbol, 18(2), 125-146. 2003. 


\begin{abstract}
Both Lakoff and Johnson (1980) and Vervaeke and Kennedy (1996), in their critique of Lakoff and Johnson, draw narrowly from a broad range of reasonable interpretations of the metaphors they analyze. Expanding the interpretations vitiates many of Vervaeke and Kennedy’s criticisms, but it supports their call for an open interpretation of groups of metaphors, and points toward a more complex elaboration of the theories put forth by Lakoff and his colleagues. The results of applying this approach to “ARGUMENT IS WAR” suggest that war is not necessarily the primary conceptual metaphor for contentious argument, as Lakoff and Johnson claim. Rather, there is a complex field of contentious interactions, ranging from simple discussions through contests to all-out war: Any and all of these can be and are used as metaphors for the others. When a word or phrase like “defend," "position," “maneuver," or "strategy" is used, there is no a priori way to determine whether the intended underlying conceptual metaphor is war, an athletic contest, or a game of chess. Similar analyses are applied to other examples from the metaphor literature, and a modification of the basic idea of conceptual mapping is proposed, in which metaphors map cognitive responses onto prototypical situations rather than mapping one specific experience or concept onto another.
\end{abstract}


ARGUMENT IS WAR - Or is it a Game of Chess?

Multiple Meanings in the Analysis of Implicit Metaphors

Lakoff and his colleagues (Lakoff \& Johnson, 1980; 1999; Lakoff \& Turner, 1989) propose an account of metaphor as implicit and conceptual. They identify numerous groups or families of metaphors, each organized around a common implicit metaphor. For many of these families of metaphors they trace the underlying metaphor to a literal concept based on embodied physical experience; on this basis they claim that most conceptual reasoning is fundamentally metaphorical, in that our abstract concepts are experienced and expressed in terms of embodied physical experience.

Vervaeke and Kennedy (1996) dispute some of the Lakoff group’s arguments and question whether the theory of conceptual metaphors is fundamentally falsifiable. Vervaeke and Kennedy make an important contribution in arguing for an essentially open interpretation of groups of metaphors, with a potential for indefinitely many levels of generality, each “'implicit' in the sense of 'waiting' or 'available' or 'apt once they are mentioned’” (1996, p. 277). However, Vervaeke and Kennedy overstate their case, since they neglect the potential for falsification through experimental research, and consider only a narrow range of reasonable extensions and interpretations of their examples; upon closer inspection these metaphors fail to support many of their claims. On the other hand, many of the metaphors produced by Lakoff and Johnson (1980) as evidence of a single implicit metaphor can likewise be interpreted in multiple ways.

In this essay I develop an extended analysis of several metaphors introduced by Vervaeke and Kennedy, Lakoff and his colleagues, and others, to show that conceptual 
metaphors such as “ARGUMENT IS WAR” often emerge from a field of inter-related concepts, all available for metaphorical application to each other as well as to external concepts, such as business and politics. The picture that emerges from a more thorough interpretation of common metaphors is more complex than Lakoff and Johnson’s (1980) original account, but I believe it preserves and extends their fundamental insights about the interpenetration of culture, thought, and language in the embodied mind.

\section{Vervaeke and Kennedy's critique of implicit metaphor theory}

In stating as a primary objective to "defend the view that some terms are literal or standardized,” Vervaeke and Kennedy (1996, p. 273) restrict language to a dichotomy, literal or metaphorical. However, evidence suggests a continuum, ranging from expressions virtually everyone would recognize as literal (including genuinely “dead” metaphors, such as "salary" and "pedigree”) to those virtually everyone would recognize as figurative (Gibbs, 1994; Goatly, 1997; Kittay, 1987; Linzey, 1997; Radman, 1997). The orientational metaphors so important to Lakoff and Johnson’s (1980) analyses (“The stock market is up," "He and his sister are very close”) are readily recognizable as metaphors, even if we do not ordinarily think of them as such (Gibbs, 1992). Their meanings have become lexicalized in the sense that we do not necessarily think of motion through space when we speak of "getting closer to a solution" or of the position of one's body when we speak of "taking a stand," but these meanings are not distinct in the sense that, for example, the contemporary meaning of salary has become distinct from “a monthly allotment of salt” (Gibbs, Beitel, Harrington, \& Sanders, 1994).

Even a new metaphor, if it strikes the hearer or reader as particularly apt, may quickly become “lexicalized” - the "Star Wars” metaphor for Reagan’s Strategic Defense 
Initiative seemed immediately apt in evoking a sense of Hollywood-originated fantasy, but after a few months the reference to the movie series of that name quickly faded from attention. By now, it is unlikely that references to a "Star Wars" defense program ordinarily evoke any more than a general sense of "fanciful, expensive, and futuristic." However, that a novel metaphor becomes lexicalized doesn't mean it ceases to function as a metaphor (Gibbs, 1994; Eubanks, 1999; 2000). When the context requires it, we are capable of elaborating on the reference, even if we ordinarily don't bother (Gentner and Bowdle, 2001; Radman, 1997).

On the need for a more thorough examination of examples. Vervaeke and Kennedy (1996) begin their critique of the idea that observable patterns in discourse are best explained by an underlying implicit metaphor with a group of orientational metaphors surrounding money, including “come into money," “run out of money,” and “fall into debt.” Vervaeke and Kennedy claim that these phrases are inflexible, pointing out that it would sound peculiar to extend them as "we came out of money," "run in money," or "rise out of debt." But this argument seems disingenuous: On the one hand, we do say that someone "comes from old money" or "rose out of poverty." On the other hand, there are also constraints on how we extend literal usages: We would not say that sugar “rose out of the bowl” (cf. Keysar \& Glucksberg, 1992).

Vervaeke and Kennedy’s (1996) other counter-examples are susceptible to similar critique. It is indeed impossible, as they contend, to understand both "she burns me up" and "she lights my fire" in terms of a root metaphor "ANGER IS HEAT," but these phrases make sense in terms of the more general "PASSION IS HEAT," as do the opposites, "cool as a cucumber," "heart like a block of ice," and "their marriage is an 
icebox" (Lakoff, 1993, makes a similar point). Granted that "she burns my fire" is ambiguous, but the literal “it burns my fire” is also awkward. Vervaeke and Kennedy’s point, that "one cannot simply group some metaphors, adduce a possible common base, and then expect derivations from the base to be apt” (1996, p. 274) is not supported by their examples, and I have not been able to think of other examples that cannot similarly be vitiated by a more careful analysis. The point that metaphors cannot be extended any which way is valid, but literal usages are subject to similar constraints (Keysar \& Glucksberg, 1992). It is often surprising how far a common metaphor can be extended, with no more attention to patterns of phrase construction than is required for a literal usage.

Similarly, Lakoff and Johnson (1980) contrast inter-related systems of metaphorical expressions, such as "argument is war" and “argument is a journey" with idiosyncratic metaphorical expressions that stand alone, e.g., "the foot of a mountain," "a table leg.” They claim that "a shoulder of the mountain” is used only by mountaineers and other specialists, and that any further extension of "mountain is a person" would be considered fanciful and literary, e.g., "the mountain had its head in the clouds." Presumably, Lakoff and Johnson would also limit “The north face of a mountain” and "the face of a cliff” to specialists; it is a testable hypothesis, whether ordinary day hikers would recognize these phrases. Lakoff and Johnson claim that to speak of an arm, rib, thigh, or leg of a mountain would not make sense, but we do speak of an "arm" and the "spine” of a mountain range, and mountains sometimes have "hogbacks."

Systems of metaphor. According to Lakoff and Johnson (1980), these idiosyncratic metaphors do not interact with other metaphors, and don’t play any central 
role in our conceptual system. However, further examination suggests that many of these metaphors are extensions of a more general conceptual system, in which the body provides a metaphorical basis for many physical and conceptual objects. Sometimes the metaphorical extension is via visual resemblance ("leg” of a table or chair, "finger" steaks and "finger” lakes, “eye” of a potato or a storm, “hogback” of a mountain), sometimes orientational (“foot” of a mountain or of a bed, "footnotes," "head" of a lake, "face” of a cliff, “arm” of a bay), sometimes functional ("head" of a family or an organization, “brains” or “eyes and ears” of an organization, "rib” of a boat or a kite, "long arm of the law," "leg” of a table or chair). There may be idiosyncratic metaphors among everyday phrases, and some everyday phrases may represent coherent families of metaphor based on singular roots or implicit metaphors, but the evidence thus far is consistent with the idea that many everyday phrases represent overlapping and interlocking systems of metaphor, affording many possible interpretations (Gentner and Bowdle, 2001; Kovecses, 1995; Radman, 1997).

Another counter-example cited by Vervaeke and Kennedy (1996, p. 274) has this same nature. "Run out of money” may be interpretable as an instance of "MONEY IS A PLACE," but it also makes sense as a subject-object inversion of "money runs out" or of the more general “RESOURCES RUN OUT," a metaphor that can be applied to many resources, including gasoline, time, energy, and patience as well as money. “I'm out of gas" can also be interpreted as a metonym for "My tank is out of gas," an inversion of the literal statement, “All the gas is out of my tank.” "I'm out of gas,” spoken at the end of a long day, is then a metaphoric reference to the original metonymic expression. Similarly, "I'm out of money" can be interpreted as a metonym for "My wallet is out of money," an 
inversion of "All the money is out of my wallet." "His luck ran out" and the inversion, "he has run out of luck" have similar meanings, as do "his money ran out" and "he has run out of money." The primary difference seems to be one of active agency: When one has "run out of money" one may be understood to have had more control over the situation than when one's money has "run out." Some people may think of an hour-glass ("the sands of time") in connection to running out of time or money; others may think of the final trickle from a water bottle. A person in the desert whose water (literally) runs out may soon find that luck and time have also (metaphorically) "run out."

\section{Supporting theoretical arguments by analyzing particular metaphors. There}

are at least three important points here. First, it appears that groups or families of metaphors overlap and possibly interlock (Eubanks, 2000; Gibbs, 1994; Grady, 1997a; Kovecses, 1995). General personification metaphors overlap with other metaphors for mountains, journeys, and the like. Metaphors based on a container of some sort overlap with other metaphors for money or luck. Literal usages sometimes overlap with metaphorical (Gibbs, et al., 1993; Keysar, 1994; Radman, 1997): Gasoline literally runs out of the tank, water literally runs out of a leaky canteen, money can run out of a hole in one’s pocket, and the sand literally runs out of the top of an hour-glass, but time, luck, and money also figuratively "run out." Second, it is incumbent upon metaphor analysts and theorists to consider carefully their examples (Cameron, 1999a), and to consider alternative reasonable interpretations. Third, and most important, it is incumbent upon metaphor analysts to match their level (and depth) of analysis to their rhetorical purposes. By considering only a limited a range of interpretation Lakoff and Johnson (1980) as well 
as Vervaeke and Kennedy (1996) often seem to set up a straw man: As soon as the range of interpretation is expanded, the alleged difficulties vanish.

Vervaeke and Kennedy (1996, p. 279) provide another group of examples that illustrate the same problem, listing a set of expressions that, they claim, point toward an implicit metaphor, “PEOPLE ARE WEAPONS.” But the person in their examples can readily be understood as a metonymic reference to "THE MOUTH IS A WEAPON," with entailments that "words are bullets," just as debaters gather "ammunition" to "shoot down” an opponent's arguments. Several other of Vervaeke and Kennedy’s examples also fall within “THE MOUTH IS A WEAPON,” including “Bill shot his mouth off again," and "Shoot” (meaning "go ahead and tell me”). The wartime motto, "Loose lips sink ships," may be an instance of the same metaphor, but it can also be taken as a metonymic reference to a sequence of actions in which chance comments are overheard by spies, etc. There is no a priori reason to prefer one reading over any other.

Consistent with one of Vervaeke and Kennedy’s (1996) primary claims, it would seem that both the level of generality at which implicit metaphors are to be identified and the family of metaphors to which a particular expression belongs are indeterminate (see also Keysar, 1994), a conclusion that is entirely consistent with Clark’s (1996) views about language use. It is no doubt true that different individuals may interpret the same expression according to different implicit metaphors, and derive different entailments (Eubanks, 2000). It does not, however, necessarily follow that the Conceptual Metaphor model is either circular or untestable. Vervaeke and Kennedy successfully demonstrate that the theory proposed by Lakoff and his colleagues cannot be refuted merely by producing other, contradictory, metaphorical expressions, but Lakoff's theory can be and 
has been tested, refined, and tested again by seeking out evidence of how people actually use and interpret metaphors (Brisard, Frisson, \& Sandra, 2001; Noveck, Bianco, \& Castry, 2001). Metaphors can indeed have multiple and indeterminate roots, as Vervaeke and Kennedy insist, but their conclusions don’t necessarily follow: The existence of multiple roots does not cancel the considerable evidence for the role of metaphor in conceptual experience and reasoning. However, their arguments do point up the need for abandoning or at least restricting the idea of singular, unique implicit metaphors.

\section{ARGUMENT IS WAR: Implicit metaphor or field of metaphorical meanings?}

Lakoff and Johnson (1980) return repeatedly to the metaphor, “ARGUMENT IS WAR,” as an example to illustrate how metaphors structure our experience of abstract concepts and ultimately shape our behavior, in this case our communicative behavior. One of Vervaeke and Kennedy's (1996) most telling points is that this and various other metaphors for argument can all be construed in terms of "a process undertaken in a certain order,” and that the various kinds of processes undertaken in a certain order can be equally well mapped onto each other, with no one process necessarily any more basic than the other (p. 276). Vervaeke and Kennedy overlook a key part of Lakoff and Johnson's argument, that metaphors for abstract concepts are, ultimately, grounded in immediate physical experience - but Lakoff and Johnson’s interpretation also seems inconsistent with this fundamental principle. Let us take another look at it.

Grounding of metaphor in direct experience. Lakoff and Johnson (1980; 1999) claim that our primary metaphorical systems are grounded first and foremost in our direct physical and social experience. All basic sensorimotor concepts are literal, and the basic experiences of dimensionality, orientation, size, etc. form a system of literal concepts, 
which then form the basis for metaphoric concepts. Children conflate subjective experiences with sensorimotor experiences; these links are established as neural pathways that persist as metaphor (“a big problem," "a close friend") long after children learn to differentiate self from world. These primary metaphors arise naturally, automatically, and unconsciously in everyday experience, then are blended into complex metaphors.

When different conceptual domains are activated at the same time, new connections are formed, leading to new inferences (Lakoff and Johnson, 1980; 1999). When these inferences are supported by physical and cultural experience, they are strengthened (Cameron, 1999b; Gibbs, 1997). Thus, metaphors are widely shared both because of the commonalities of embodied experience (larger objects commonly pose greater challenges than smaller ones; the proximity of caregivers is commonly associated with gratification of needs) and because culturally prominent metaphors are reinforced in everyday conversation. Complex metaphors coalesce into systems of metaphors that serve to structure abstract concepts and provide a basis for reasoning, for drawing inferences about the target based on relationships observed in the source (Lakoff \& Johnson, 1999). Because they are widely shared within a culture, complex metaphors provide a basis for abstract concepts such as communication (Gibbs, 1997), morality (Lakoff, 1996) and international trade (Eubanks, 2000).

Experiential grounding for metaphors of argument. Lakoff and Johnson discuss “ARGUMENT IS WAR" in several passages, and return to it repeatedly as an example of a complex conceptual metaphor. In their most elaborate discussion Lakoff and Johnson (1980, pp. 77ff.) list several relevant characteristics of argument: One participant has a position, the other participant has a different position, both positions 
matter inasmuch as one must surrender for the other to achieve victory, the difference of opinion becomes a conflict, both participants plan strategy and marshal their forces, attack the other's claims and defend their own, maneuver to achieve a stronger position, occasionally retreat before a stronger argument, then attempt to counterattack, etc. Lakoff and Johnson then point out that these elements of an argument correspond to elements of the concept, “war.”

However, many of the elements on this list also correspond to elements of concepts such as “chess match,” "bridge game” (Vervaeke \& Kennedy, 1996), and other competitive activities (Eubanks, 2000). Chess itself is often used as a metaphor for war (Eubanks, 2000) - and war is sometimes used as a metaphor for chess (and other games). The names of some chess pieces, in English, suggest a war metaphor (castle, knight) but names of other pieces suggest a political metaphor (bishop, queen). War is also frequently used as a metaphor for athletic competition, and for business competition - but again, the converse is also true. Most of the metaphorical expressions Lakoff and Johnson (1980) cite as evidence for an underlying metaphor, “ARGUMENT IS WAR” are also consistent with “ARGUMENT IS CHESS” or “ARGUMENT IS BOXING.”

Given the small number of people in the U.S. who have directly experienced war, it is not easy to see how "ARGUMENT IS WAR" can be grounded in direct physical or social experience, except through media portrayals of war or by way of a chain of extensions built on more direct experience, such as "WAR IS BOXING." On the other hand, several of the other activities within this group of inter-related concepts are grounded in direct physical and social experience, and thus are directly available for metaphorical understanding of argument - and of war. From a very early age, children 
engage in heated disputes that lead to verbal and occasionally to physical violence. They engage in competitive contests and games, and in contests of will with siblings, peers, parents, and other adults. Although it is dubious that children have any realistic concept of war before they reach adolescence (if then), they certainly have well-developed schemas for physical and verbal fighting, contests, and games.

Children probably acquire the warlike metaphors of their culture in the same way they acquire vocabulary for other concepts beyond their personal experience, through communication, both interpersonal and mediated. But how do children come to understand the concept of war, if not by metaphorical elaboration of their own embodied experience of interpersonal conflict? It is likely that our experience of both argument and war are grounded in the common experience of frustrated desires and the consequent conflict of wills, a sequence of events experienced by children from infancy.

In short, we need not look to organized adult warfare for an experiential basis to ground our understanding of argument; we have a rich experiential basis much closer to hand. I am not arguing that we never understand argument in terms of warfare; indeed, I suspect most of us have found ourselves in the kind of argument where one or the other antagonist is in a mood to "take no prisoners" and will settle for nothing less than “unconditional surrender,” and the stakes escalate beyond ordinary competition. I am suggesting, in concurrence with Vervaeke and Kennedy (1996), that the same metaphorical expressions are used in a variety of social contexts, of which all-out war is only the most extreme. War is indeed often used as a metaphor for interpersonal argument, but argument is also sometimes used as a metaphor for war, and games are often used as a metaphor for both argument and war (see also Eubanks, 2000). 
However, I do not agree with Vervaeke and Kennedy (1996, p. 276) that it necessarily follows that no process is more basic than the others. If we are to take seriously Lakoff and Johnson’s (1980) proposal that abstract concepts, as well as novel physical and social experiences (such as the experience of war, to those fortunate enough never to have experienced it directly), are understood by metaphorical extension of immediate “embodied” (physical and social) experience, then the processes of interpersonal competition and conflict are more basic than the processes of either war or formal academic argument, if only in the sense that they are experienced first, and the other forms of conflict that come later are at least initially understood in terms of the earlier experiences. That does not imply, of course, that the later forms of conflict, once they have been experienced (if only vicariously, through novels, films and news reports), do not in turn provide powerful metaphors for expressing certain aspects of more routine forms of conflict, including argument.

The case for discrete types of metaphors. Grady (1997a, b; Grady, Taub, \& Morgan, 1996) argue, on the basis of a reanalysis of Lakoff and Johnson’s (1980) discussion of THEORIES ARE BUILDINGS, for a distinction between primary and compound metaphors. Several aspects of buildings fail to map onto theories (floors, walls, ceiling, etc.), and no direct experiences correlate theorizing with building a structure; Grady and his colleagues point out that, if the metaphor is analyzed as a compound of LOGICAL STRUCTURE IS PHYSICAL STRUCTURE and PERSISTING IS REMAINING ERECT, these difficulties disappear. However, Grady's analysis reifies the verbal manifestation of a conceptual metaphor: The propositional form, in this instance THEORIES ARE BUILDINGS, is but “a mnemonic for a set of ontological 
correspondences...” (Lakoff, 1993: 207). The attempt to map building parts such as floors, walls, ceiling, etc. onto theories assumes that metaphorical entailments and extensions are pushed by the vehicle rather than pulled by whatever users desire to convey about the topic. In the spirit of Lakoff's (1993) analysis, it would seem sufficient that a user casting about for a concept that expresses a particular aspect of theory find an instance of that concept in some aspect of buildings. It seems reasonable to interpret THEORIES ARE BUILDINGS in terms of LOGICAL STRUCTURE IS PHYSICAL STRUCTURE and PERSISTING IS REMAINING ERECT, but it also seems reasonable to seek a more direct interpretation, in terms of the metaphor user's immediate experience with buildings as exemplars of structured relationships among parts. Indeed, all of these seem to belong to and instantiate different aspects of a single underlying conceptual field. Grady's (1997a) proposal is quite different from Lakoff's (1993) idea that metaphorical mappings are sometimes organized in “inheritance hierarchies.” Lakoff gives the example of LOVE IS A JOURNEY (“Our relationship is going nowhere”), which makes use of the structure and inherits the entailments of A PURPOSEFUL LIFE IS A JOURNEY, which in turn fits into the event structure metaphor, that maps events onto location and motion through space. Grady's proposal also differs from the distinction between the lexicalized but still lively metaphors (such as EMOTION IS HEAT and MORE IS UP) that form the core of Lakoff and Johnson's (1980) argument on the one hand and the "novel metaphors" discussed at length by Lakoff and Turner (1989) and Lakoff (1993: 229 ff.). These do not necessarily fall into discrete categories, but form a continuum, ranging from the metaphors such as EMOTION IS HEAT and MORE IS UP, grounded in experiences that begin in very early childhood, through metaphors 
such as ARGUMENT IS PHYSICAL CONFLICT and SOCIAL OBLIGATIONS ARE PHYSICAL CONSTRAINTS, grounded in experiences that begin somewhat later in childhood, to self-consciously literary metaphors such as the old favorite of metaphor theorists, “Juliet is the sun," and the vernacular "You are my sunshine” (Davis \& Mitchell, 1940).

Verbal combat vs. rational argument. Lakoff and Johnson (1980, pp. 62ff) contrast the kind of verbal combat associated with "argument is war" with rational argument, in which participants are expected to follow an architectural rather than a military metaphor, to support their positions with reasoning based on evidence rather than defend their position with aggressive tactics such as intimidation, threat, or insult, or with evasive tactics such as appeal to authority, belittling, evading the issue, flattery, and bargaining. In spite of our stated preference for cool rationality, they claim, we tend to conceive of and discuss rational argument in terms of war metaphors, and supposedly rational arguments often rely heavily on the "irrational” tactics of combat, even within academic, legal, and other contexts where reason is presumed to reign supreme.

However, many of the tactics Lakoff and Johnson mention (intimidation, threat, insult) are more closely related to one-on-one interpersonal conflict than to organized warfare, and others belong to domains quite removed from physical violence (e.g., evading the issue, bargaining, and flattery). Rational argument is sometimes undermined by tactics metaphorically drawn from organized warfare, but it is also undermined by tactics metaphorically drawn from competitive games or the showmanship of a professional stage magician (bluffing, distraction, sleight of hand). During the American Civil War, Confederate General Magruder drew on his talent for stagecraft to formulate 
effective defensive tactics (Catton, 1963) - but that does not make theatrical terms into war metaphors! Rather, the application of dramatical terms ("theater of operations, “stage an invasion”) to war is itself metaphorical. In sum, the examples Lakoff and Johnson give to support their contention that argument even in an academic context is structured in terms of war are more consistent with the view that common metaphors can be interpreted in terms of multiple conceptual metaphors or metaphor systems. It is an empirical question, which of the various metaphorical systems is tapped by a particular reader or listener in any particular instance.

Argument within a field of conflict metaphors. It appears that our culture has a large, complex, and densely interconnected conceptual field, a set of schemas for competition and conflict ranging from friendly, low ego-involvement games through highly competitive games, shouting matches, fisticuffs, brawls, all the way to full-scale war (see Eubanks, 2000; Gibbs, 1994; 1997). Within this conceptual field, we readily transfer expressions associated with one form of competition or conflict to others. Moreover, another form of indirect speech is often at play here, the ironical use of understatement and overstatement. Using understatement, we metaphorically transfer terms from fencing, chess, and boxing to speak of one army (in actual warfare) “parrying the thrust," "countering the move," or "blocking the punch" of another army; using overstatement, we metaphorically transfer terms from actual warfare to speak of a quarterback “throwing the long bomb” or an orator “overwhelming his opponent's defenses." We also use overstatement in saying that an orator "brought his opponent to his knees,” a metaphor based on person-to-person combat or athletic competition rather than on warfare between armies (Eubanks, 2000, makes a similar point). Some terms are 
associated with more than one type of competitive or aggressive activity: It is not evident that "strategy" and "position" are adapted to chess from warfare, rather than the reverse. Other terms, such as “submission,” seem more immediately connected with group hierarchy and rituals of dominance than with warfare. To paraphrase von Clausewitz (1968), war is itself a continuation of dominance rituals by other means.

Metaphor as categorization. Glucksberg and Keysar (1993) propose that a metaphor establishes a superordinate category, to which both vehicle and topic belong, that includes all objects having the relevant qualities. They give the example, “cigarettes are time bombs,” which establishes a superordinate category of potentially deadly objects that seem harmless at first but eventually kill. Chiappe \& Kennedy (2001) object that it is difficult to see what the superordinate category view adds to the search for similarities associated with the implied simile view. Moreover, both the "superordinate category" model and the "search for similarities” model are, at least in some instances, inherently circular: Consider another of Glucksberg and Keysar’s examples, “My job is a jail,” which places "my job” into "the category of things that the metaphor vehicle jail typifies - situations that are unpleasant, confining, difficult to escape from, unrewarding, and so on” (Glucksberg, Keysar, \& McGlone, 1992, p. 578). Cigarettes and time bombs do share the literal category-defining quality of leading eventually to death but, in the absence of legalized slavery, a job does not share the qualities that define jails except in a sense that is already metaphorical (Ritchie, 2003; see also Lakoff, 1993).

The category of social contentions. Nevertheless it is useful to look at some families of metaphors in terms of superordinate categories. Lakoff and Johnson (1980) concede that it is often difficult to distinguish metaphor from subcategorization, because 
it is not always clear whether two activities are of the same or different kinds. They give as an example, “an argument is a fight." If we think of "fight” in general terms, an argument is a fight that doesn’t involve blows, and a war is a fight that involves much more than blows. Their point is well-taken, and it can usefully be extended much further. It may be useful to think of a very general category of situations, in which two parties have opposing ideas, beliefs, intentions, etc., that may or may not lead to violent conflict. We might think of this general category as “All Abstractly Similar Contending Activities” (Eubanks, 2000) or, more simply, as the category of social contentions.

Within the general category of social contentions are several sub-categories, including physical fights and other forms of conflict, as well as situations in which the contention is primarily between factual propositions, and little of emotional or social import is at stake. When this second sort of contention arises, all participants are less concerned that their own proposals are accepted than that the correct or most useful proposal is accepted. When two friends, hiking through the woods, come to a fork in the trail, what matters most is that they both take the trail that leads to their destination, not that the other person accept their own view as to which trail is the correct one.

Other sub-categories include those in which material possessions are at stake, ranging from control of territory to possession of a house following a divorce, and those in which intangible assets such as social status and self-esteem are at stake. The subcategories often blur into one another: A simple discussion about which trail leads to the destination can involve a threat to social status and self-esteem if one’s abilities as an outdoorsman seem to be in question. Ordinarily, an academic dispute is presumed to be like the case of hikers coming to a fork in the trail: What matters most is that we select 
the best theory, and thus avoid wasting time and resources. But as Lakoff and Johnson (1980) point out, issues of prestige and self-esteem often become implicated in an academic dispute, and indeed material wealth (in the form of grants, promotions, and so forth) are often at stake (see also Sweetser, 1992). In short, we seem to have a continuum of social contentions, running from a simple game or an intellectual discussion at one end through violent inter-personal combat (a fist-fight or duel) to group combat (a gang rumble or all-out war) at the other: The higher the perceived stakes, and the lower the commitment to continued social interactions among the participants, the farther we are likely to move toward the violent end of the continuum.

Multiple meanings or metaphorical meanings? Vervaeke and Kennedy (1996) argue for a "multiple meaning” account of terms such as attack and defend, which are applied both to warfare and to arguments. They acknowledge that attack may have originated in a metaphorical application, but argue that it has come to have two separate and independent meanings. Consider, “Jane considered his attack on her argument as an attack on her intellectual integrity.” Vervaeke and Kennedy point out that we could substitute a synonym such as "refutation of" for the first use of attack and a different synonym (“assault”) for the second use, but these could not be interchanged without a radical change of meaning: An assault on an argument is not the same as an attack on an argument, and a refutation of one's intellectual integrity doesn't make sense at all. From this, Vervaeke and Kennedy conclude that there are actually two separate words, attack as a synonym for assault and attack as a synonym for attempt to refute.

But compare attack to a true homograph, ring, “a circular object or figure” and ring, "to give forth a clear, resonant sound.” These are distinct words, derived from 
different roots, that happen coincidentally to be spelled and pronounced the same in English. By contrast, attack is one word, with a single root, and all of its many meanings have in common a sense of aggression, hostility, and a lack of restraint, in contrast with apparent synonyms such as "try to disprove" and "try to refute." To attack an argument is not the same as to refute an argument, to give a counter-example, or to construct a counter-argument. These are indeed synonyms, but they are substitutable only in a particular context, and they are not equivalents. It is precisely the association, perhaps with war, perhaps with a fist-fight, but at least with some form of aggressive conflict, that differentiates our response to an attack from our response to a refutation or a counterargument. This sense of aggression and hostility can only derive from a metaphorical association with conflict, although not necessarily with war per se. To attack an opponent's argument is to do something more than merely to try to refute it, and to “demolish” an opponent's argument is to do something much more than merely to “demonstrate its inconsistencies." That something more is approximately the sense of conflict and no-holds-barred antagonism suggested by the metaphorical association with childhood name-calling and fist-fights, as well as with adult activities such as mugging and all-out war. It would not seem unreasonable for Jane to interpret an "attack" on her argument as an “attack” on her intellectual integrity, but it would seem unreasonable if she should interpret an "attempt to refute" her argument as an "assault" on her intellectual integrity. We would expect, or at least condone, an angry and resentful response to an “attack," but we would expect a more reasoned and calm response to an “attempt to refute.” 
Conceptual blending. Lakoff and Johnson (1980; 1999) explain the metaphorical mapping process in terms of underlying concepts, claiming that we actually experience the target concept in terms of the source. Thus, an exasperated worker who complains, “This job is a jail” is inviting the listener to experience the supervisor as a prison guard, the workplace as a barred cell, and the employment contract as a sentence. A more general account, that subsumes Lakoff and Johnson’s “conceptual metaphors,” is provided by conceptual blending theory (Fauconnier \& Turner, 1998; 2002; see also Coulson \& Matlock, 2001). According to this approach, the conceptual structures of two or more "input spaces” (e.g., topic and source) are selectively combined into a new, separate, "blended” mental space (the metaphor), which is then available for further blending. "Men are wolves” (Gentner \& Bowdle, 2001) combines the schema of men who are single-minded and emotionally uninvolved in pursuit of sexual gratification with a pre-existing schema of wolves as heartless and vicious predators, itself a prior blend of various terrors once associated with life at the edge of a wilderness and the observed and imagined behavior of actual wolves in pursuit of their prey. "My job is a jail" blends the mental image of the speaker's working conditions with a pre-existing schema of jail, itself a blend of various emotions associated with social and physical constraints and mediated accounts of life in a jail or prison. Conceptual blending seems to provide a non-circular explanation for metaphor interpretation, although I am not yet convinced that it represents more than a useful metaphor for poorly-understood neurological processes, and it remains unclear what kind of data can falsify it (Gibbs, 2001).

Are metaphorical meanings fixed? Speakers sometimes use words with little consideration of entailments, and hearers sometimes think very little about these 
entailments while interpreting an utterance (Steen, 1999). As Vervaeke and Kennedy suggest, a novel metaphor "may be interpreted very differently by different audiences...” (1996, p. 283); following Clark (1996), I would suggest that most metaphors, including many of the most familiar, are subject to this indeterminacy. When a term such as “attack,” “defend,” or “strategy” appears in a discussion of an argument, we cannot be sure whether any particular person will associate the term with chess, boxing, or all-out war - or with nothing beyond an abstract concept. How any particular speaker intends a metaphor to be interpreted, and how any particular hearer does interpret the metaphor, can never be absolutely determined.

This indeterminacy of metaphors can be the occasion for serious miscommunication: Consider an argument between friends or spouses, described by one participant, thinking of the argument as a chess match, in terms such as "strategy," “attack," and "defend." In chess, one hopes the opponent will be willing to repeat the engagement in the future, win or lose, but in war, one hopes to win so overwhelmingly that there will be no future engagement. If the other participant associates these terms with war, the result is likely to be an unhappy one (Reddy, 1993; Schoen, 1993; Lakoff \& Johnson, 1980). As Vervaeke and Kennedy suggest (albeit with respect to novel metaphors), elucidating the conditions under which an individual will make one or another set of metaphorical connections, or none at all, is “an important task for empirical scientists” (1996, p. 283).

Does metaphor influence thought? Vervaeke and Kennedy insist that "the idea that metaphors govern thought needs to be firmly restricted. Rather, a metaphor is often chosen from a set of alternative metaphors with widely differing implications to express 
an idea that is literal” (1996, p. 283). I do not see these as mutually exclusive ideas although "governs" may be rather too strong a metaphor, and "literal” is difficult to define precisely (Gibbs, 1994; Kittay, 1987; Rumelhart, 1993). If many of our abstract concepts are themselves shaped by structural metaphors, as Lakoff and Johnson (1980; 1999) contend, then we do not have very many truly "literal” ideas to express, beyond the basic ideas that are grounded in direct physical experience, like "I fell down," "I stood up,” and "I ate a carrot."

Metaphor can be hypothesized to influence thought in at least two ways, without contradicting the hypothesis that people more or less deliberately select metaphors to express their ideas as clearly as possible. First, to the extent that the language most readily available for discussing an abstract concept is shaped by a certain set of metaphors, we will find it difficult to express contradictory ideas about that concept without inventing new metaphors (Lakoff and Johnson, 1980; 1999; Reddy, 1993; Schoen, 1993). Second, to the extent that a hearer is induced to process the entailments of a metaphor, these entailments will become part of the meaning of the concept in the present context (Kovecses, 1995). It is, indeed, for this reason that a speaker would choose one metaphor rather than another: It would be no use choosing an expression based on "LOVE IS A JOURNEY" rather than "LOVE IS A NATURAL DISASTER” if the entailments particular to each implicit metaphor could not be expected to have a distinctive influence on the thoughts and responses of the listener.

\section{Metaphor as field of associated cognitive responses}

I would like to propose an alternative account, that goes part of the way with Vervaeke and Kennedy, yet preserves the most important insights from Lakoff and 
Johnson’s analysis. As suggested by Vervaeke and Kennedy (1996, p. 282), words like attack and defend have, through various metaphorical extensions, taken on a broader set of meanings, connected not only with discourse about war and other situations of conflict, but also with aggressive forms of argument and aggressive interactions in general. Such a metaphorical extension creates a "field” of meanings (Katz, 1992), including the entailments, images, responses, and expectations evoked by the metaphor vehicle, as well as with the various topics to which the metaphor is typically or routinely applied. It little matters whether the conflict metaphors discussed by Lakoff and Johnson (1980) originate with war, with childhood rough-and-tumble, or with other forms of conflict; they carry a set of potential meanings derived from all of these, and from their application to chess, bridge, basketball, and school debate tournaments as well. This full range of entailments, images, responses and expectations is available as part of the common base of language and experience (Clark, 1996; Eubanks, 2000; Gibbs, 1994; 1997) whenever the words that belong to a group of metaphors are used, although only some of them will be intended by a speaker, and not all of them will be accessed by someone who hears or reads the metaphor.

As Clark (1996) observes, a hearer often interprets an utterance (literal or metaphorical) to mean something different from what the speaker intended, and the problem of coordinating what the speaker is taken to mean is by no means trivial. In many cases, including stock phrases such as “the stock market is falling," a preferred meaning has been so completely lexicalized as to eliminate much of the ambiguity. However, even some stock phrases continue to afford a certain level of ambiguity: If "the grass is greener on the other side of the fence," does the speaker engage in self- 
criticism because her neighbor works harder (“has a prettier lawn”) or does she indulge in envy for her neighbor who has more opportunities ("has better forage”)? Often the context provides clues, as Romeo’s line, “But soft! What light through yonder window breaks?" helps us make sense of the following, "It is the east, and Juliet is the sun" (Shakespeare, 1952: Act Two Scene II, 3-4), but as the persistent critical speculations about Shakespeare’s metaphor demonstrate (e.g., Searle, 1993), context doesn’t necessarily eliminate ambiguity (cf. Stern, 2000).

Non-directional metaphors. In some cases, metaphors are one-way streets, and the field of meanings is derived entirely from the vehicle. Phrases associated with “ $A$ LIFE IS A JOURNEY” call upon those entailments of journey that seem applicable to life; the reverse, “A JOURNEY IS A LIFE,” does not make sense (except perhaps in some very peculiar context). However, when a set of vehicles and targets (war, athletic games, and argument) all have characteristics that shed light on the others, the metaphors are reversible, and the fields of meaning created by reversing the metaphors may become partially blended (Turner \& Fauconnier, 1999). Thus, it can make sense to describe war in terms of argument or argument in terms of war, war in terms of boxing or boxing in terms of war. The entailments are of course reversed (Gibbs, 1994): “an athletic contest is war" or "trade is war" (Eubanks, 2000) invests sports or trade with aggressiveness and ruthlessness, but "war is an athletic contest" or "war is trade” invests war with a sense of rules and fair play on the one hand or with a sense of rational calculation of potential gains and losses on the other. The fields of meaning created by these transposed metaphors can blur into one another, until it does not seem strange to use both, together, as a metaphor for argument, business, or politics, and in some cases it seems to be 
difficult to establish with any certainty whether the vehicle of a metaphorical expression is intended to be “war," "sports," or “chess.”

Metaphors as mapping of cognitive responses. Finally, I would like to propose a modification to the “conceptual metaphor” approach (Lakoff \& Johnson, 1980), and suggest that, at least in some instances, metaphors evoke a set of responses (emotions, social relationships, cultural and physical expectations, etc.), that may be associated primarily with the vehicle, or may be uniquely evoked by the combination of vehicle and topic. It is these expectations and emotional responses that establish the basis for comparison and define the "superordinate category” (Keysar \& Glucksberg, 1992) to which a topic is assigned by a metaphor, and not necessarily any of the particular qualities of the metaphor vehicle. Thus, we need not find any qualities common to Juliet and the sun in order to make sense of Romeo’s declaration that “Juliet is the sun" (Shakespeare, Act II, Scene II, line 3). From the preceding phrases, "What light through yonder window breaks? It is the east," we know that Romeo wishes to tell us that the sight of Juliet's face in the window arouses in him the same sort of responses and expectations that the rising sun elicits. From the immediately subsequent lines, beginning “Arise, fair sun, and kill the envious moon, Who is already sick and pale with grief...” we further learn that the sight of Juliet's face arouses in him the same expectations, with respect to her potential competitors (Rosaline in particular, mentioned by Mercutio in the immediately preceding scene), that the sun arouses with respect to the moon and stars. There are no qualities common to a young woman and the sun that could possibly define a superordinate category, and none is needed: What their metaphorical juxtaposition 
brings to the fore is the kind of emotions, comparisons, and expectations they each arouse.

At least in the case of metaphors that express such widely shared experience that they have become stock expressions in a culture, the correlations evoked by a metaphor are not between particular qualities or types, but between emotions, sensations, and expectations on the one hand and the situations that typically evoke these cognitive states on the other. The correlated cognitive states may be activated by the juxtaposition of topic and vehicle, as with "Juliet is the sun," or they may be activated by the vehicle alone: Tourangeau and Rips (1991) found that subjects can readily interpret blank metaphors, of the form "X is the Napoleon of birds." Similarly, in THEORIES ARE BUILDINGS (Grady, 1997a), our evaluative responses and expectations to theories draw upon another blank metaphor, “X IS A BUILDING” ( “X has a firm foundation,” " $X$ is falling apart,” “construct a solid X”), and “My job is a jail” (Keysar \& Glucksberg, 1992) instantiates a more general blank metaphor, “X IS CONFINEMENT.”

In "My job is a jail," the metaphor is established, not by "situations that are unpleasant, confining, difficult to escape from, unrewarding, and so on” (Glucksberg, Keysar, \& McGlone, 1992, p. 578) but by our responses to these situations. A similar sense of constraint is captured in a number of related expressions, for example, an adolescent may complain that "this house is a prison," or, if he is really frustrated, " $a$ concentration camp." An old dysphemism for a domineering spouse is "ball and chain," and we speak of being "stuck in a rut," "mired in indecision," "bound hand and foot," "tied down," and so forth. What these all have in common is a feeling of restricted action, choices, or options. The associated emotion may be reactance, as when an 
adolescent describes his home and family as a "prison” or "concentration camp," dissonance reduction, as when a worker describes her job as a "jail” (and thereby denies her actual ability to quit and seek an alternative job), or even an ironical expression of affection and commitment, as in "Blest be the tie that binds" (Fawcett, 1782) and "I keep the ends out for the tie that binds" (Cash, 1956). The sense of incapacity to change a situation, nullify a social or emotional commitment, or find the answer to a problem or puzzle is almost impossible to express except through some metaphor associated with bondage or confinement.

As with the metaphorical field surrounding confrontation, people begin from an early age to experience feelings of frustration, reactance, and cognitive dissonance - as well as the more positive feelings of challenge and competitive stimulation - when they find themselves physically, socially, or intellectually constrained. Infants and young children experience unpleasant physical constraint in their cribs and high chairs or when adults or older children block their access to fragile or dangerous items, but they also delight in being loosely constrained in an adult's limbs while they try to wriggle free. Later, as they become socialized, children experience social constraint when some desired action is prohibited by adults, when faced with a choice between equally desirable objects or courses of action, when constrained by a previously given promise or by the threat of social disapproval. The subjective experiences elicited by social constraints and intellectual puzzles are similar in various ways to each other and to those elicited by physical constraints, and the many forms of physical and social constraint are ready to hand for expressing and understanding these experiences. In conversations and in mass media we encounter a large field of other constraints that provide a ready source 
of metaphors, including jail, prison, ball and chain, briar patches, tangled yarn, jungles, indebtedness, mazes, puzzles, monastic vows, and so on.

The complex feelings aroused by physical or social constraints are associated in our memories, and they do form a "category" of sorts. But the category is defined, not in terms of "things that are confining, punitive, and impossible to escape” (Glucksberg, Keysar \& McGlone, 1992, p. 578), but in terms more like "things that give me feelings and expectations associated with constraint, challenge, frustration, and reactance.” Glucksberg et al. contend that “jail” is the prototypical member of such a category, but as with the "category" of social confrontations, there are many exemplars, each expressing a subtly different aspect of the underlying experience, including “strait jacket,” "tied up,” “chained,” “in hock,” and “married” (as in “married to a theory”).

\section{Conclusion:}

Although I concur with the general thrust of Vervaeke and Kennedy’s (1996) critique, I have argued that they overstate their case, in part because of an excessively narrow interpretation of their examples. Close analysis of both commonplace and original metaphors can help to illuminate the embodied interactions among language, thought, and culture, but the interpretations must be thorough, open to additional interpretive paths, and, at least in principle, informed by the variety of rhetorical and cultural contexts in which the metaphors are actually used.

I have extended Vervaeke and Kennedy's criticism of the proposition that a collection of metaphors is necessarily interpretable only with respect to a single implicit metaphor at a single level, arguing that the phrases Lakoff and Johnson interpret in terms of “ARGUMENT IS WAR” emerge from a field of inter-related concepts, including 
athletic contests, games, and interpersonal quarrels as well as war and argument: The associations of each of these concepts are available for metaphorical application to the others as well as to external concepts such as business and politics. I have argued that it is more consistent with Lakoff and Johnson's theory of metaphorical grounding to base our understanding of the entire set of contention metaphors on the sort of competitive games and interpersonal conflict that are experienced from early childhood throughout the life-span. A similar analysis can be applied to any complex field of metaphors, as I have shown with respect to metaphors of constraint.

It is more complex, but the picture that emerges from a more extended and thorough interpretation of common metaphors leaves the broad outlines of Lakoff and Johnson’s (1980) original account more or less intact. Although there is insufficient space here to work out the details, I believe the two accounts are compatible, and a combination of both may be required for a complete understanding of metaphor. The account I propose seems particularly consistent with Lakoff's (1993) point, previously cited, that the propositional expression of a conceptual metaphor is but a mnemonic, and not to be accorded independent status. In addition to Lakoff and Johnson's neat pyramid of conceptual metaphors, building from the most basic physical experiences of orientation, pain, and so forth toward extremely abstract concepts such as love, causality, and God, we may find that we have several recursive, continually reconstructed fields of figurative / literal concepts, in which the metaphorical mappings link cognitive responses and expectations to an overlapping continuum of prototypical experiences, and we may often be unable to determine with certainty how a particular speaker intends or a particular listener interprets a given metaphor. 


\section{Author's Note}

I would like to thank an anonymous reviewer, and especially Dr. Ray Gibbs, for their many thoughtful and provocative comments on earlier drafts of this essay, which has been considerably improved as a result. Any remaining oversights, omissions, or mistakes are of course entirely my own responsibility. 


\section{References}

Brisard, F., Frisson, S., and Sandra, D. (2001). Processing unfamiliar metaphors in a self-paced reading task. Metaphor and Symbol, 16(1\&2), 87-108.

Cameron, L. (1999a). Identifying and describing metaphor in spoken discourse data. Ch. 6, pp. 105-134 in Cameron, L., and Low, G. (Eds.), Researching and applying metaphor. Cambridge, England: Cambridge University Press.

Cameron, L. (1999b). Operationalising ‘metaphor’ for applied linguistic research. Ch. 1, pp. 3-28 in Cameron, L., and Low, G. (Eds.), Researching and applying metaphor. Cambridge, England: Cambridge University Press.

Cash, J. R. (1956). I walk the line. Nashville, KY: Legacy Records; re-released in 1969 by Columbia Records on Johnny Cash at San Quentin.

Catton, B. (1963). Terrible Swift Sword. NY, NY: Doubleday.

Chiappe, D. L., and Kennedy, J. M. (2001). Literal bases for metaphor and simile. Metaphor and Symbol, 16, 249-276.

Clark, H. H. (1996). Using language. Cambridge, England: Cambridge University Press.

Clausewitz, C. von (1968). On War. Translated from the French by Terence Kilmartin. New York, W. W. Norton.

Coulson, S., and Matlock, T. (2001). Metaphor and the space structuring model. Metaphor and Symbol, 16(3\&4), 295-316.

Davis, J., and Mitchell, C. (1940). You are my sunshine. Nashville, TN: Peer International Corporation. 
Eubanks, P. (2000). A war of words in the discourse of trade: The rhetorical constitution of metaphor. Carbondale IL: Southern Illinois University Press.

Eubanks, P. (1999). The story of conceptual metaphor: What motivates metaphoric mappings? Poetics Today, 20(3), 419-442.

Fauconnier, G., and Turner, M. (2002). The way we think: Conceptual blending and the mind's hidden complexities. New York, NY: Basic Books.

Fauconnier, G., and Turner, M. (1998). Conceptual integration networks. Cognitive Science, 22(2), 133-187.

Fawcett, J. (1976). Blest be the tie that binds. In Carmichael, R., Seal, C., Burgess, D., DeVries, R., Merrill, L., Cole, B., Howe, B., Stover, D., and McCracken, J., Eds., The New Church hymnal. Nashville, TN: Lexicon Music.

Gentner, D., and Bowdle, B. F. (2001). Convention, form, and figurative language processing. Metaphor and Symbol, 16, 223-247.

Gibbs, R. W., Jr. (2001). Evaluating contemporary models of figurative language understanding. Metaphor and Symbol, 16(3\&4), 317-333.

Gibbs, R. W., Jr. (1997). Taking metaphor out of our heads and putting it into the cultural world. Pp. 145-166 in Gibbs, R. W., Jr., and Steen, G. J. Metaphor in cognitive linguistics. Selected papers from the fifth international cognitive linguistics conference. Amsterdam: John Benjamins Publishing Co.

Gibbs, R. W. Jr. (1994). The poetics of mind: Figurative thought, language, and understanding. Cambridge, England: Cambridge University Press.

Gibbs, R. W. Jr. (1992). When is metaphor? The idea of understanding in theories of metaphor. Poetics Today, 13(4), 575-606. 
Gibbs, R. W. Jr., Beitel, D. A., Harrington, M., and Sanders, P. E. (1994). Taking a stand on the meaning of stand. Journal of Semantics, 14, 231-251.

Gibbs, R. W., Jr., Buchalter, D. L., Moise, J. F., and Farrar, W. T. IV. (1993). Literal meaning and figurative language. Discourse Processes, 16, 387-403.

Glucksberg, S., and Keysar, B. (1993). How metaphors work. In A. Ortony (Ed.), Metaphor and thought ( $2^{\text {nd }}$ ed, pp. 401-424). Cambridge, England: Cambridge University Press.

Glucksberg, S., Keysar, B., and McGlone, M. S. (1992). Metaphor understanding and accessing conceptual schema: Reply to Gibbs(1992). Psychological Review, 99, 578-581.

Goatly, A. (1997). The language of metaphors. London: Routledge. Grady, J. E. (1997a). THEORIES ARE BUILDINGS revisited. Cognitive Linguistics, 8-4, 267-290.

Grady, J. (1997b). A typology of motivation for conceptual metaphor: Correlation vs. resemblance. Pp. 79-100 in Gibbs, R. W., Jr., and Steen, G. J. Metaphor in cognitive linguistics. Selected papers from the fifth international cognitive linguistics conference. Amsterdam: John Benjamins Publishing Co.

Grady, J., Taub, S., and Morgan, P. (1996). Primitive and compound metaphors. Pp. 177-187 in Goldberg, A. (ed.), Conceptual structure, discourse and language. Stanford, CA: CSLI Publications.

Katz, A. N. (1992). Psychological studies in metaphor processing: Extensions to the placement of terms in semantic space. Poetics Today, 13(4), 607-632. 
Keysar, B (1994). Discourse context effects: Metaphorical and literal interpretations. Discourse Processes, 18, 247-269.

Keysar, B., and Glucksberg, S. (1992). Metaphor and communication. Poetics Today, 13(4), 633-658.

Kittay, E. F. (1987). Metaphor: Its cognitive force and linguistic structure. Oxford, England: Oxford University Press.

Kovecses, Z. (1995). American friendship and the scope of metaphor. Cognitive Linguistics, 6-4, 315-346.

Lakoff, G. (1996). Moral politics: What conservatives know that liberals don't. Chicago, IL: University of Chicago Press.

Lakoff, G. (1993). The contemporary theory of metaphor. In Ortony, A. (ed.), Metaphor and Thought, $2^{\text {nd }}$ Ed, pp. 202-251. Cambridge, England: Cambridge University Press.

Lakoff, G., and Johnson, M. (1980). Metaphors we live by. Chicago, IL: University of Chicago Press.

Lakoff, G., and Johnson, M. (1999). Philosophy in the flesh: The embodied mind and its challenge to western thought. New York NY: Basic Books.

Lakoff, G., and Turner, M. (1989). More than cool reason: A field guide to poetic metaphor. Chicago, IL: University of Chicago Press.

Linzey, T. (1997). Toward a life-span account of metaphor. Metaphor and Symbol, 12, 189-204.

Noveck, I. A., Bianco, M., and Castry, A. (2001). The costs and benefits of metaphor. Metaphor and Symbol, 16(1\&2), 109-121. 
Radman, Z. (1997). Difficulties with diagnosing the death of a metaphor. Metaphor and Symbol, 12, 149-157.

Reddy, M. J. (1993). The conduit metaphor: A case of frame conflict in our language about language. In Ortony, A. (ed.), Metaphor and Thought, $2^{\text {nd }} E d$, pp. 164201. Cambridge, England: Cambridge University Press.

Ritchie, L. D. (2003). Categories and Similarities: A Note on Circularity. Metaphor and Symbol, 18, 49-53.

Rumelhart, D. E. (1993). Some problems with the notion of literal meanings. In A. Ortony (Ed.), Metaphor and thought ( $2^{\text {nd }}$ ed, pp. 71-82). Cambridge, England: Cambridge University Press.

Schoen, D. A. (1993). Generative metaphor: A perspective on problem-setting in social policy. In Ortony, A. (ed.), Metaphor and Thought, $2^{\text {nd }}$ Ed, pp. 137-163. Cambridge, England: Cambridge University Press.

Searle, J. R. (1993). Metaphor. In A. Ortony (Ed.), Metaphor and thought $\left(2^{\text {nd }}\right.$ ed, pp. 83-111). Cambridge, England: Cambridge University Press.

Shakespeare, W. (1952). Romeo and Juliet. Pp. 902-939 in Alexander, P., ed., William Shakespeare: The complete Works. New York: NY: Random House.

Steen, G. J. (1999). Analyzing metaphor in literature: With examples from William Wordsworth’s “I wandered lonely as a cloud.” Poetics Today, 20(3), 499-522.

Stern, J. (2000). Metaphor in Context. Cambridge, MA: The MIT Press.

Sweetser, E. (1992). English metaphors for language: Motivations, conventions, and creativity. Poetics Today, 13(4), 705-724. 
Turner, M., and Fauconnier, G. (1999). A Mechanism of Creativity. Poetics Today, 20(3), 397-418.

Tourangeau, R., and Rips, L. (1991). Interpreting and evaluating metaphors. Journal of Memory and Language 30, 452-472.

Vervaeke, J. and Kennedy, J. M. (1996). Metaphors in language and thought: Falsification and multiple meanings. Metaphor and Symbolic Activity, 11(4), 273-284.

Von Clausewitz, C. (1968). On War. (T. Kilmartin, Trans.) New York: Norton. 